\section{Kidney \\ Blood Pressure Research}

\title{
Cell-Based Therapies in Acute Kidney Injury (AKI)
}

\author{
Daniel Patschan ${ }^{a} \quad$ Ivo Buschmann ${ }^{a} \quad$ Oliver Ritter $^{a} \quad$ Andreas Kribben $^{b}$
}

annere Medizin I, Kardiologie, Angiologie, Nephrologie, Klinikum Brandenburg, Medizinische Hochschule Brandenburg, Brandenburg, 'Klinik für Nephrologie, Universitätsklinikum Essen, Essen, Germany

\section{Key Words}

Aki • Cell therapy $\bullet$ IPSCs • MSCs • PACs

\begin{abstract}
Acute kidney injury frequently occurs in hospitalized patients all over the world. The prognosis remains poor since specific therapies for promoting kidney regeneration / repair are still missing. In recent years cell-based strategies have improved AKI outcomes under experimental circumstances. Four groups of cells, each of them displaying certain biological and functional characteristics have been evaluated in AKI, induced Pluripotent Stem Cells (iPSCs), Spermatagonial Stem Cells (SSCs), Proangiogenic Cells (PACs) and Endothelial Colony Forming Cells (ECFCs), and Mesenchymal Stem Cells (MSCs). All of these have been documented to stabilize either parameters of kidney excretory dysfunction and / or certain morphological parameters. The mechanisms responsible for AKI protection include direct (cell incorporation) and indirect processes, the latter being mediated by humoral factors and particularly by the production of so-called extracellular vesicles. Cell-derived vesicular organelles have been shown to carry pro-regenerative micro-RNA molecules which stabilize the vascular and tubular function. The first trials in humans have been initiated, the majority of such trials employs MSCs. However, any transfer of cell-based strategies in the clinical practice is potentially associated with significant difficulties. These include cell availability, tolerance and competence. The article intends to summarize essential informations about all of the four populations mentioned above and to discuss implications for the management of human AKI.
\end{abstract}

\section{Introduction}

Acute kidney injury remains a substantial problem in hospitalized patients worldwide with increasing incidences in recent years. It is being estimated that $15-18 \%$ of all individuals treated in european hospitals suffer from an acute decline in kidney excretory function during the course of the disease [1]. This situation significantly results from aging of the population in general, going in parallel with increased cumulative morbidity. However, the 


\section{Kidney Blood Pressure Research}

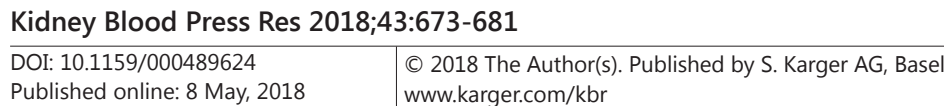

Patschan et al.: Cells in AKI

prognosis of the syndrome, which may occur under various circumstances, has not significantly been improved since the mid 1990s. Overall mortality rates range between 3-5\% with a particularly high risk in patients treated at the ICU (30-50\%) [2]. Survival rates decrease with progessive loss of kindey excretory function according to the AKIN-criteria [3]. The lowest survival rates have been identified in subjects with a malignant disease, chemotherapy-associated sepsis and dialysis-requiring AKI (90\%) [4]. The 2012 KDIGO guidelines offer criteria for diagnosing AKI, they are based on dynamic changes in the serum creatinine concentration [5]. It has widely been accepted that serum creatinine is a marker of poor quality in terms of early AKI detection. Alternative biomarkers have been evaluated over the last 15-20 years with none of them truly being suitable for replacing creatinine [6]. Thus, in most cases AKI is diagnosed too late for appropriate management of the respective cause and the ensuing consequences on kidney function and structure. Another problem which accounts for the poor prognosis of AKI is related to the management per se. So far, specific pro-renegerative strategies are missing. The majority of therapeutic measures is intended to avoid further damage. It becomes evident that new or alternative strategies are needed.

In recent years, cell-based therapies have increasingly been established in the clinic. The most expanded area in this respect is stem cell treatment in oncology. By supplying host-derived or allogeneic bone marrow-derived hematopoietic stem cells, a number of individuals suffering from hemato-oncological disorders may be stabilized in a transient manner or even be cured. In addition, the so-called population of Chimeric Antigen Receptor (CAR) T cells has revolutioned the treatment of relapsing or refractory B cell malignancies [7-9]. Recently, Dellepiane and colleagues extensively summarized the literature on cell-based therapies in AKI and kidney transplantation [10]. Particulary in the second field, numerous trials have been initiated, employing either Mesenchymal Stem cells (MSCs), or Hematopoietic Stem Cells (HSCs), or regulatory T cells. A common characteristic of all approaches is the induction of immuno-tolerance towards allogeneic cells / antigens in the graft.

In terms of cell-based AKI therapy, two essential problems arise. The first problem is the heterogeneity of causes, the second the highly complex structure of the kidney. The most common cause of AKI, transient or prolonged renal hypoperfusion induces numerous homeostatic alterations in tubules, glomeruli, vessels, and the interstitium [11, 12], respectively. The multitude of cellular and humoral processes involved may hardly be accessible by modulatory effects of a single population of injected cells. Other causes of AKI are glomerular or vascular or primarily interstitial disorders, all of these characterized by disease-specific mechanisms responsible for tissue damage and malfunction. Most experimental AKI studies performed so far employed either renal ischemia and / or tubulo-toxic substances in order to impair kidney function. Meanwhile, certain homogenous or heterogenous cell populations have been applied in experimental AKI. In addition, several studies in humans have been initiated.

Aim of the article is to report on the progress that has been achieved in the field and to point towards potential perspectives for the clinician. The following cell populations shall be discussed in detail: induced Pluripotent Stem Cells (iPSCs), Spermatagonial Stem Cells (SSCs), Proangiogenic Cells (PACs) and Endothelial Colony Forming Cells (ECFCs), and Mesenchymal Stem Cells (MSCs).

\section{Terminology}

A few terminological remarks may preceed the discussion of individual cell populations. 'Totipotency' reflects the ability of cells to further differentiate into any cell type of an organism. Strictly taken, this characteristic behavior is exclusively fulfilled by the zygote. Pluripotent cells in contrast can give rise to almost any cell type, the only exception being placental cells. Multipotent cells may differentiate into cells originating from one germ layer and unipotent cells are progenitors of one well-defined cell population. 


\section{Kidney Blood Pressure Research}

Kidney Blood Press Res 2018;43:673-681

DOI: 10.1159/000489624

Published onlıne: 87Vay, 2018

(C) 2018 The Author(s). Published by S. Karger AG, Base www.karger.com/kbr

\section{induced Pluripotent Stem Cells (iPSCs)}

The 2012 nobel prize in medicine / physiology was awarded to Sir J. B. Gordon and to S. Yamanaka for 'the discovery that mature cells can be reprogrammed to become pluripotent' [13]. Until then, embryonic stem cells were the only cell population displaying a pluripotent behaviour. iPSC were initially generated from adult fibroblasts by activating the following genes: Oct3/4, Sox2, c-Myc, and Klf4 [14]. Meanwhile, a vast amount of studies from other groups has been published, substantially confirming the observations made by Gordon and Yamanaka. A medline-based search using the term 'induced pluripotent stem cells' reveals more than 10, 000 individual citations. Thus, the field has dramatically emerged. The first kidney-related investigations of iPSCs were published in 2011 and 2012. Thatava et al. originated iPCSs from keratinocytes of individuals with End-Stage Renal Disease (ESRD) of different etiology (Lupus nephritis and Autosomal Dominant Polycystic Kidney Disease) [15]. Song and colleagues employed iPSCs as podocytic progenitors [16]. In 2012 finally, Lee et al. transdifferentiated murine fibroblasts into iPSCs, subsequently followed by their subcutaneous administration in NOD-SCID mice [17]. Cells gave rise to cartilage, smooth musculature, and neurons which was in line with their pluripotent abilities. Next, iPSCs were administered in experimental AKI, either intraperitoneally or intravenously or directly into the renal artery. The latter procedure was associated with a significant improvement in blood urea nitrogen levels. Surprisingly, administered cells did not further differentiate in neither tubular epithelial nor endothelial nor glomerular cells despite their ability to reduce tubular apoptosis, interstitial inflammation, and oxidative stress, respectively. Thus, iPSCs, although capable to differentiate into almost any cell type which can originate from all three germ layers, acted by indirect mechanisms and not by substituting specific cells in a direct manner. Lately, Yuan and colleagues [18] found lower blood urea nitrogen and creatinine levels and improved morphological parameters post-AKI, under the administration of so-called human-induced pluripotent stem cell-derived mesenchymal stromal cells (hiPSC-MSCs) to be critically mediated by extracellular vesicles. We will later discuss this new field more in detail. The following sections will always highlight the respective mechanism(s) of cell-mediated AKI-protection. These informations are critical for any approach that is intended for employing cell-based therapies in the clinic.

\section{Spermatogonial Stem Cells (SSCs)}

(Almost) every male hosts SSCs in the testes, they are precursors of spermatocytes [19]. Thus, SSCs are unipotent under physiological conditions. Nevertheless, artificial procedures can be applied in order to reprogram SSCs into cells with pluripotent behavior. Two methods have been reported, the first involves SSC culturing in leukemia inhibitory factor-containing medium, the second requires co-culturing of SSCs and Mitomycine-C treated embryonic fibroblasts from mice [20]. The ensuing cell population has been defined as Germline cell-derived Pluripotent Stem Cells (GPSCs) [21]. Both cell types, SSCs and GPSCs have been administered in experimental AKI. Wu et al. observed intratubular incorporation of Y-chromosome+ cells in female mice after SSC injection [22]. Nevertheless, the mentioned study did not evaluate post-AKI outcome parameters such as serum creatinine. Another study, published by De Chiara and colleagues employed GPSCs instead and found the in vitro-differentiation of renal tubular like cells accompanied by significant AKI-protection in the long-term: interstitial fibrosis and inflammation were reduced at week 6 post-injury [20]. As oposed to iPSCs, (SSCs and) GPSCs apparently act by direct mechanisms and not by modifying the post-ischemic milieu through paracrinic and / or other vesicular-dependent mechanisms. 


\section{Kidney Blood Pressure Research}

Patschan et al.: Cells in AKI

\section{Mesenchymal Stem Cells (MSCs)}

Among all cell populations applied for therapeutic purposes in AKI, MSCs have been evaluated in the largest number of experimental and even clinical investigations so far. They may be isolated and expanded from bone marrow, adipose tissue, umbilical cord and other sources [23]. In culture, they display a fibroblast-like morphology and display a characteristic, although not specific cell-surface marker pattern (positiv: CD73, CD90 und CD105; negative: CD11b, CD14, CD19, CD34, CD45, CD79a and HLA-DR) [24]. Their multipotent capacity is reflected by the cells' ability to differentiate into chondroblasts, osteoblasts, adipocytes, and myocytes, respectively [25]. Hallmark studies came from the group around Westenfelder. A first study from 2005 [26] reported MSC isolation from the bone marrow, followed by iron labeling and systemic administration in post-ischemic rats. Cells accumulated in the renal cortex as shown by magnetic resonance tomography and kidney excretory function was significantly preserved at days 2 and 3 after cell therapy (serum creatinine concentration). Tögel et al. [27] found comparable AKI-protective effects (quantification of serum creatinine) but failed to detect injected cells to be incorporated in either tubules or vessels or other specific (sub)compartments of the kidney. Additional studies revealed the subcellular mechanisms of MSC-mediated tissue-protection to be predominantly indirect in nature. Firstly, the cells have been shown to secrete a heterogenous amount of paracrinic substances [28]. Secondly, they produce and excrete or shed extracellular vesicules [29]. In recent years, the topic extracellular vesicles has significantly caught the attention of several groups around the globe. Among the substances secreted by MSCs are monocyte chemoattractant protein-1 (MCP-1/ CCL2), IL-6, IL-8, fibronectin, periostin, collagen, and metalloproteinase inhibitors. In addition, the cells produce growth factors such as insulin-like growth factor 1 (IGF-1), hepatocyte growth factor (HGF), and vascular endothelial growth factor (VEGF) [28]. Microvesicles are small organelles in the size of 50-200 nm, released by shedding from biologically active cells. They may contain certain bio-active substances such as microRNA molecules and proteins with anti-apoptotic and immunomodulatory effects [30-33]. The functional relevance of MSC-generated microvesicles has been documented by studies in which the vesicular fraction alone was effective in preventing experimental AKI [34]. One may argue which functional component, the MSC secretome (paracrinic substances) or the microvesicular fraction, is more relevant in terms of protecting the kidney and other organs from acute and chronic damage. Nevertheless, MSCs have meanwhile been employed in numerous clinical trials. As reported by Peired and colleagues [28], several clinical investigations have been initiated in subjects with kidney diseases. Lately, Dellepiane summarized trials currently performed in individuals at higher AKI risk [10]. Five studies were named, the respective NCT numbers are: NCT00511407 (Renal Assist Device vs. CVVHD); NCT01602328 (AKI in cardiac surgery subjects); NCT00733876 (AKI in cardiac surgery subjects); NCT01602328 (AKI in cardiac surgery subjects); NCT01275612 (Cisplatin treatment in solid organ cancers). At this moment we would like to shortly name some essential inclusion criterium of the named investigations: cisplatin-induced AKI, post-cardiac surgery AKI (three times). The last section will recall this information. In addition to AKI, MSCs are currently evaluated in more than 10 trials related to allograft rejection in kidney and liver transplant recipients. For more information we would like to refer to Dellepiane and colleagues [10].

\section{Proangiogenic Cells (PACs) and Endothelial Colony Forming Cells (ECFCs)}

These two groups represent the so-called Endothelial Progenitor Cell population (EPCs) which has initially been identified by Asahara and colleagues [35]. In recent years it has seriously been questioned whether EPCs truly exist or not. For a long period, proangiogenic cells were thought to represent EPCs, as reflected by different terms such as early EPCs or ear- 


\section{Kidney Blood Pressure Research}

Kidney Blood Press Res 2018;43:673-681

DOI: $10.1159 / 000489624$

Published online: 8 May, 2018

(C) 2018 The Author(s). Published by S. Karger AG, Base www.karger.com/kbr

ly Endothelial Outgrowth Cells (eEOCs) [12]. Meanwhile, it seems acceptable to negate any substantial progenitor cell capacity of early EPCs. Basile and Yoder proposed an alternative terminology instead, ProAngiogenic Cells (PACs), which seems a reasonable approach [36]. PACs without any doubt act vasoprotective or proangiogenic, since numerous experimental trials succsessfully applied the cells in ischemic disease models such as coronary and peripheral artery and cerebrovascular disease [37-42]. The cells can be isolated and expanded from the mononuclear blood cell population of certain vertebrates. In culture, PACs appear after 5-7 days [37]. A number of studies intended to identify a characteristic PAC cell surface marker pattern. Nevertheless, a specific set of markers is still missing. Overall, PACs display hematopoietic and endothelial properties, with the respective balance between these two phenotypes depending on the procedure employed for cell expansion [37]. Thus, PACs are everything but homogenous in nature. ECFCs on the other hand may represent genuine precursors of mature endothelial cells [43]. Comparably to PACs, ECFCs can be extracted from mononuclear blood cells as well but culturing requires significantly longer periods (3-8 weeks) [44]. Both subpopulations, PACs and ECFCs have sucessfully been administered in experimental AKI [44-48]. In addition, several strategies have been established in order to augment AKI-protective effects of particularly PACs [46, 47, 49-51]. In almost all of the mentioned studies, kidney excretory function was evaluated by serum creatinine levels and additionally by certain morphological parameters such as acute tubular damage shortly (48 hours) after ischemia. The first study was published in 2006 [48]. Ischemic preconditioning of the kidney induced translocation of autologous murine PACs into the medulla of both kidneys. Isolated medullary mononuclear cells, enriched by PACs protected recipient animals from ischemic AKI (lower serum creatinine). In later studies, PACs were isolated and expanded from blood and spleen of C57/B16N mice and injected post-ischemia to recipient animals. It appeared that AKI-protection was less efficient if the ischemic period lasted longer [51]. Thus, further studies were intended to augment the AKI-protective capacity of PACs and several pharmacological agonists of the cells were identified. Among those were melatonin [47], 8-0-cAMP [51], Bone Morphogenetic Protein-5 (BMP-5) [46], and Angiopoietin-1 [50] and -2 [49]. A more recent study showed that PACs administration post-AKI did not only prevent the kidney from acute loss of excretory function but also stabilizeed certain structural outcome parameters such as interstitial fibrosis and loss of peritubular capillaries [52]. PACs predominantly act by indirect mechanims, whereas ECFCs also operate as substitutes of damaged endothelial cells [37]. Human studies are missing yet.

\section{Cell-based therapies in human AKI - perspectives and current limitations}

No matter how promising certain experimental approaches for AKI-prevention, namely those employing cell-based procedures, may appear at first sight, several limitations will hardly be resolved in the near future. These limitations make it almost unrealistic to establish cell therapies in the clinical practice. We discussed the following issues in the past [12] but would like to summarize the essential problems once more. The first problem that needs to be addressed is related to the exact timing of cell administration. In an ideal situation, cells would be applied at the moment of AKI onset, e.g. shortly after renal ischemia. Unfortunately, acute kidney dysfunction does neither cause any typical symptoms, comparable to cardiac ischemia for instance nor are any marker molecules available that allowed a fast and early detection of AKI. From the clinicians' perspective it is impossible to define the exact moment at which AKI evolves. Even if it became possible to predict the moment, cells for therapeutic administration should be available more or less immediately. To obtain proangiogenic cells, to give an example, usually requires between 5 and 7 days [53]. Therefore, AKI must be diagnosed almost a week in advance. Another problem concerns the compatibility between cells and recipient. Strictly speaking, cell therapy must be defined as tissue transplantation. One may object that MSCs or PACs or SSCs are obtainable from the future recipient. Although 


\section{Kidney Blood Pressure Research}

Fig. 1. Mechanisms of cell-mediated AKIprotection. It needs to be noted that direct repair has exclusively been reported for Spermatogonial Stem Cells (SSCs) and Endothelial Colony forming Cells so far. iPSCs, MSCs and PACs predominantly act by indirect processes (paracrinic activity and microvesicle-dependent mechanisms).

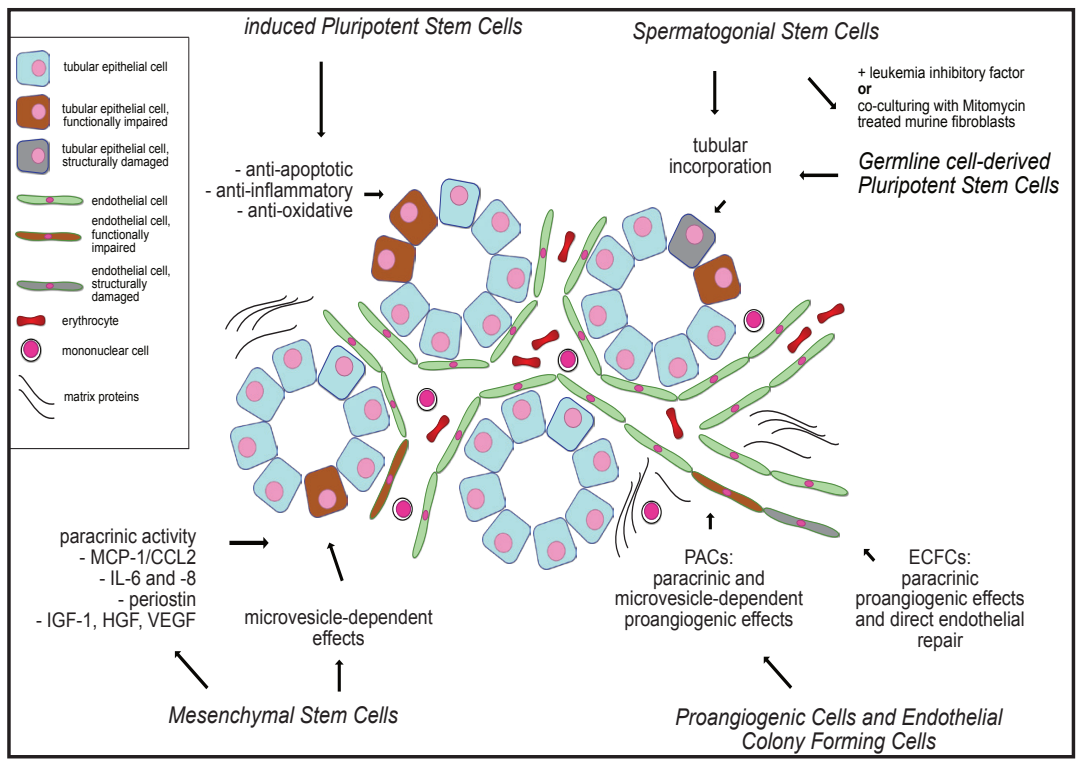

true, such an approach assumes consistently and comparably protective biological effects of cells isolated from different hosts. Bone marrow-derived cell competence has been shown to decline under diabetic circumstances [54], defective PAC regeneration was documented in subjects with higher dardiovascular risk [55]. There are of course certain situations in which cells, whatever their origin and biological behavior may be, can be applied in a controlled manner: post-cardiac surgery, chemotherapy with tubulo-toxic drugs such as cisplatin. There are currently three clinical trials performed in AKI, all of these initiated in subjects at very high AKI risk (see Mesenchymal Stem Cells). However, the largest quantity of AKI events occurs in individuals with sepsis or heart failure, therefore under conditions, that do not allow to predict the exact moment at which the kidney is significantly compromised.

Thus, if considered pessimistic, one may discard cell therapies in AKI as future option in hospitals worldwide. Nevertheless, we suppose that the mechanisms by which cells act within the post-ischemic microenvironment may be utilized for therapeutic purposes. As discussed earlier, MSCs, PACs / ECFCS, and iPSCs predominantly mediate AKI-protection through indirect processes, e.g. by modulating the humoral milieu in a paracrinic manner and / or by secreting microvesicles in close proximity to tubules and the vasculature. In a 2012 published investigation by Cantaluppi and colleagues [45], PAC-derived microvesicles alone prevented animals from AKI. The study also revealed certain microRNA molecules to be responsible for promoting tissue repair. In our opinion, the ex vivo synthesis of microvesicles for therapeutic purposes appears difficult to say the least. Therefore, our current investigations focus on the secretome of PACs, on the heterogenous group of humoral factors synthesized and secreted by proangiogenic cells under native and artificial conditions. By possibly identifying a pattern of PAC-derived proteins that mediate kidney protection / repair in acute situations, new perspectives for AKI management may arise. Whether the overall goal, to improve AKI outcomes and costs can be achieved, at least in part, remains speculative at the moment.

\section{Conclusion}

We nevertheless conclude that any direct application of cells in daily clinical practice will most likely not become a suitable option. Fig. 1 depicts mechanisms of cell-mediated AKI protection. 


\section{Kidney \\ Blood Pressure Research}

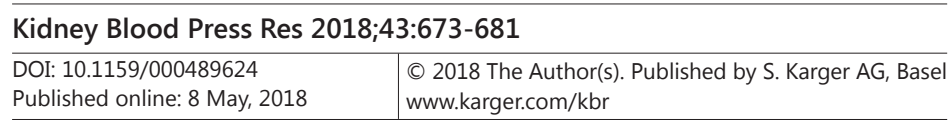

Patschan et al.: Cells in AKI

\section{Acknowledgements}

The studies of D. Patschan are supported by the Deutsche Forschungsgemeinschaft, the Jackstädt-Stiftung and the European Foundation for the Study of Diabetes.

\section{Disclosure Statement}

The authors declare no conflicts of interest regarding the publication of this article.

\section{References}

1 Bienholz A, Wilde B, Kribben A: From the nephrologist's point of view: diversity of causes and clinical features of acute kidney injury. Clin Kidney J 2015;8:405-414.

2 Srisawat N, Kellum JA: Acute kidney injury: definition, epidemiology, and outcome. Curr Opin Crit Care 2011;17:548-555.

3 Duan S, Liu Q, Pan P, Xu J, Liu N, Li Y, Liu H, Peng Y, Sun L, Liu F: [RIFLE and AKIN criteria for mortality and risk factors of acute kidney injury in hospitalized patients]. Zhong Nan Da Xue Xue Bao Yi Xue Ban 2013;38:1243-1252.

4 Heeg M, Mertens A, Ellenberger D, Müller GA, Patschan D: Prognosis of AKI in malignant diseases with and without sepsis. BMC Anesthesiol 2013;13:36.

5 Khwaja A: KDIGO clinical practice guidelines for acute kidney injury. Nephron Clin Pract 2012;120:c179184.

-6 Schrezenmeier EV, Barasch J, Budde K, Westhoff T, Schmidt-Ott KM: Biomarkers in acute kidney injury pathophysiological basis and clinical performance. Acta Physiol Oxf Engl 2016; DOI:10.1111/apha.12764.

7 Hartmann J, Schüßler-Lenz M, Bondanza A, Buchholz CJ: Clinical development of CAR T cells-challenges and opportunities in translating innovative treatment concepts. EMBO Mol Med 2017;9:1183-1197.

$>8$ Xia AL, Wang XC, Lu YJ, Lu XJ, Sun B: Chimeric-antigen receptor T (CAR-T) cell therapy for solid tumors: challenges and opportunities. Oncotarget 2017;8:90521-90531.

-9 Levine BL, Miskin J, Wonnacott K, Keir C: Global Manufacturing of CAR T Cell Therapy. Mol Ther Methods Clin Dev 2017;4:92-101.

10 Dellepiane S, Medica D, Quercia AD, Cantaluppi V: The exciting "bench to bedside" journey of cell therapies for acute kidney injury and renal transplantation. J Nephrol 2017; DOI:10.1007/s40620-017-0384-Z.

11 Devarajan P: Update on mechanisms of ischemic acute kidney injury. J Am Soc Nephrol JASN 2006;17:1503-1520.

12 Patschan D, Kribben A, Müller GA: Postischemic microvasculopathy and Endothelial Progenitor Cell-based therapy in ischemic AKI - update and perspectives. Am J Physiol Renal Physiol 2016;ajprenal.00232.2016.

13 The Official Web Site of the Nobel Prize: The Nobel Prize in Physiology or Medicine 2012 [cited 2017, Nov 21]. Available from: https://www.nobelprize.org/nobel_prizes/medicine/laureates/2012/.

-14 Takahashi K, Yamanaka S: Induction of pluripotent stem cells from mouse embryonic and adult fibroblast cultures by defined factors. Cell 2006;126:663-676.

15 Thatava T, Armstrong AS, De Lamo JG, Edukulla R, Khan YK, Sakuma T, Ohmine S, Sundsbak JL, Harris PC, Kudva YC, Ikeda Y: Successful disease-specific induced pluripotent stem cell generation from patients with kidney transplantation. Stem Cell Res Ther 2011;2:48.

16 Song B, Smink AM, Jones CV, Callaghan JM, Firth SD, Bernard CA, Laslett AL, Kerr PG, Ricardo SD: The directed differentiation of human iPS cells into kidney podocytes. PloS One 2012;7:e46453.

17 Lee PY, Chien Y, Chiou GY, Lin CH, Chiou CH, Tarng -C: Induced pluripotent stem cells without c-Myc attenuate acute kidney injury via downregulating the signaling of oxidative stress and inflammation in ischemia-reperfusion rats. Cell Transplant 2012;21:2569-2585. 


\section{Kidney \\ Blood Pressure Research}

Patschan et al.: Cells in AKI

18 Yuan X, Li D, Chen X, Han C, Xu L, Huang T, Dong Z, Zhang M: Extracellular vesicles from human-induced pluripotent stem cell-derived mesenchymal stromal cells (hiPSC-MSCs) protect against renal ischemia/reperfusion injury via delivering specificity protein (SP1) and transcriptional activating of sphingosine kinase 1 and inhibiting necroptosis. Cell Death Dis 2017;8:3200.

19 de Rooij DG: The nature and dynamics of spermatogonial stem cells. Dev Camb Engl 2017;144:3022-3030.

$\checkmark 20$ De Chiara L, Fagoonee S, Ranghino A, Bruno S, Camussi G, Tolosano E, Silengo L, Altruda F: Renal cells from spermatogonial germline stem cells protect against kidney injury. J Am Soc Nephrol 2014;25:316-328.

-21 Guan K, Nayernia K, Maier LS, Wagner S, Dressel R, Lee JH, Nolte J, Wolf F, Li M, Engel W, Hasenfuss G: Pluripotency of spermatogonial stem cells from adult mouse testis. Nature 2006;440:1199-1203.

-22 Wu D, He D, Li X, Liu Z: Differentiations of transplanted mouse spermatogonial stem cells in the adult mouse renal parenchyma in vivo. Acta Pharmacol Sin 2008;29:1029-1034.

23 Gregory CA, Prockop DJ, Spees JL: Non-hematopoietic bone marrow stem cells: Molecular control of expansion and differentiation. Exp Cell Res 2005;306:330-335.

24 Dominici M, Le Blanc K, Mueller I, Slaper-Cortenbach I, Marini F, Krause D, Deans R, Keating A, Prockop Dj, Horwitz E: Minimal criteria for defining multipotent mesenchymal stromal cells. The International Society for Cellular Therapy position statement. Cytotherapy 2006;8:315-317.

25 Franco Lambert AP, Fraga Zandonai A, Bonatto D, Cantarelli Machado D, Pêgas Henriques JA: Differentiation of human adipose-derived adult stem cells into neuronal tissue: does it work? Differ Res Biol Divers 2009;77:221-228.

-26 Lange C, Tögel F, Ittrich H, Clayton F, Nolte-Ernsting C, Zander AR, Westenfelder C: Administered mesenchymal stem cells enhance recovery from ischemia/reperfusion-induced acute renal failure in rats. Kidney Int 2005;68:1613-1617.

-27 Tögel F, Hu Z, Weiss K, Isaac J, Lange C, Westenfelder C: Administered mesenchymal stem cells protect against ischemic acute renal failure through differentiation-independent mechanisms. Am J Physiol Ren Physiol 2005;289:F31-42.

28 Peired AJ, Sisti A, Romagnani P: Mesenchymal Stem Cell-Based Therapy for Kidney Disease: A Review of Clinical Evidence. Stem Cells Int 2016;2016:4798639.

-29 Lai RC, Yeo RWY, Lim SK: Mesenchymal stem cell exosomes. Semin Cell Dev Biol 2015;40:82-88.

30 Chen Y, Qian H, Zhu W, Zhang X, Yan Y, Ye S, Peng X, Li W, Xu W: Hepatocyte growth factor modification promotes the amelioration effects of human umbilical cord mesenchymal stem cells on rat acute kidney injury. Stem Cells Dev 2011;20:103-113.

-31 Uccelli A, Moretta L, Pistoia V: Mesenchymal stem cells in health and disease. Nat Rev Immunol 2008;8:726-736.

-32 Le Blanc K, Mougiakakos D: Multipotent mesenchymal stromal cells and the innate immune system. Nat Rev Immunol 2012;12:383-396.

33 Galderisi U, Giordano A: The gap between the physiological and therapeutic roles of mesenchymal stem cells. Med Res Rev 2014;34:1100-1126.

-34 Ju GQ, Cheng J, Zhong L, Wu S, Zou XY, Zhang GY, Gu D, Miao S, Zhu YJ, Sun J, Du T: Microvesicles derived from human umbilical cord mesenchymal stem cells facilitate tubular epithelial cell dedifferentiation and growth via hepatocyte growth factor induction. PloS One 2015;10:e121534.

-35 Asahara T, Murohara T, Sullivan A, Silver M, van der Zee R, Li T, Witzenbichler B, Schatteman G, Isner JM: Isolation of putative progenitor endothelial cells for angiogenesis. Science 1997;275:964-967.

-36 Basile DP, Yoder MC: Renal endothelial dysfunction in acute kidney ischemia reperfusion injury. Cardiovasc Hematol Disord Drug Targets 2014;14:3-14.

-37 Fadini GP, Losordo D, Dimmeler S: Critical reevaluation of endothelial progenitor cell phenotypes for therapeutic and diagnostic use. Circ Res 2012;110:624-637.

38 Fan Y, Shen F, Frenzel T, Zhu W, Ye J, Liu J, Chen Y, Su H, Young WL, Yang GY: Endothelial progenitor cell transplantation improves long-term stroke outcome in mice. Ann Neurol 2010;67:488-497.

-39 Kaneko Y, Tajiri N, Shinozuka K, Glover LE, Weinbren NL, Cortes L, Borlongan CV: Cell therapy for stroke: emphasis on optimizing safety and efficacy profile of endothelial progenitor cells. Curr Pharm Des 2012;18:3731-3734. 


\section{Kidney \\ Blood Pressure Research}

Kidney Blood Press Res 2018;43:673-681

DOI: $10.1159 / 000489624$

Published online: 8 May, 2018

(c) 2018 The Author(s). Published by S. Karger AG, Base

Patschan et al.: Cells in AKI

-40 Martí-Fàbregas J, Crespo J, Delgado-Mederos R, Martínez-Ramírez S, Peña E, Marín R, Dinia L, Jiménez-Xarrié E, Fernández-Arcos A, Pérez-Pérez J, Querol L, Suárez-Calvet M, Badimon L: Endothelial progenitor cells in acute ischemic stroke. Brain Behav 2013;3:649-655.

-41 Moubarik C, Guillet B, Youssef B, Codaccioni J-L, Piercecchi M-D, Sabatier F, Lionel P, Dou L, Foucault-Bertaud A, Velly L, Dignat-George F, Pisano P: Transplanted late outgrowth endothelial progenitor cells as cell therapy product for stroke. Stem Cell Rev 2011;7:208-220.

-42 Devanesan AJ, Laughlan KA, Girn HR, Homer-Vanniasinkam S: Endothelial progenitor cells as a therapeutic option in peripheral arterial disease. Eur J Vasc Endovasc Surg 2009;38:475-481.

-43 Paul J Critser MCY: Endothelial Colony Forming Cell role in neoangiogenesis and tissue repair. Curr Opin Organ Transplant 2010;15:68-72.

44 Patschan D, Schwarze K, Tampe B, Zeisberg M, Patschan S, Müller GA: Endothelial Colony Forming Cells (ECFCs) in murine AKI - implications for future cell-based therapies. BMC Nephrol 2017;18:53.

45 Cantaluppi V, Gatti S, Medica D, Figliolini F, Bruno S, Deregibus MC, Sordi A, Biancone L, Tetta C, Camussi G: Microvesicles derived from endothelial progenitor cells protect the kidney from ischemia-reperfusion injury by microRNA-dependent reprogramming of resident renal cells. Kidney Int 2012;82:412-427.

46 Patschan D, Schwarze K, Lange A, Meise N, Henze E, Becker JU, Ptschan S, Müller GA: Bone Morphogenetic Protein-5 and early Endothelial Outgrowth Cells (eEOCs) in acute ischemic kidney injury (AKI) and 5/6-chronic kidney disease. Am J Physiol Ren Physiol 2013;305:F314-322.

47 Patschan D, Hildebrandt A, Rinneburger J, Wessels JT, Patschan SA, Becker JU Henze E, Krüger A, Müller GA: The hormone Melatonin stimulates renoprotective effects of early outgrowth endothelial progenitor cells in acute ischemic kidney injury. Am J Physiol Ren Physiol 2012;302:F1305-F1312.

48 Patschan D, Krupincza K, Patschan S, Zhang Z, Hamby C, Goligorsky MS: Dynamics of mobilization and homing of endothelial progenitor cells after acute renal ischemia: modulation by ischemic preconditioning. Am J Physiol Ren Physiol 2006;291:F176-185.

-49 Patschan D, Backhaus R, Elle HJ, Schwarze K, Henze E, Becker JU, Patschan S, Müller GA: Angiopoietin-2 modulates eEOC-mediated renoprotection in AKI in a dose-dependent manner. J Nephrol 2013;26:667-674.

50 Patschan D, Rinneburger J, Idrizi N, Backhaus R, Schwarze K, Henze E, Patschan S, Müller GA: Angiopoietin-1 treated early endothelial outgrowth cells (eEOCs) are activated in vitro and reduce renal damage in murine acute ischemic kidney injury (iAKI). BMC Nephrol 2013;14:227.

51 Patschan D, Patschan S, Wessels JT, Becker JU, David S, Henze E, Goligorsky MS, Müller GA: Epac-1 activator 8-0-cAMP augments renoprotective effects of syngeneic [corrected] murine EPCs in acute ischemic kidney injury. Am J Physiol Ren Physiol 2010;298:F78-85.

52 Patschan D, Schwarze K, Henze E, Patschan S, Müller GA: The endothelial-to-mesenchymal transition and endothelial cilia in EPC-mediated postischemic kidney protection. Am J Physiol Renal Physiol 2016;310:F679-F687.

53 Patschan D, Patschan S, Muller GA: Inflammation and microvasculopathy in renal ischemia reperfusion injury. J Transpl 2012;2012:764154.

54 Chen J, Li H, Addabbo F, Zhang F, Pelger E, Patschan D, Park HC, Kuo MC, Ni J, Gobe G, Chander PN, Nasjletti A, Goligorsky MS: Adoptive transfer of syngeneic bone marrow-derived cells in mice with obesity-induced diabetes: selenoorganic antioxidant ebselen restores stem cell competence. Am J Pathol 2009;174:701711.

55 Huang PH, Chen JW, Lin SJ: Effects of Cardiovascular Risk Factors on Endothelial Progenitor Cell. Acta Cardiol Sin 2014;30:375-381. 